\title{
Knowledge About Breast Cancer Risk-Factors, Breast Screening Method And Practice Of Breast Screening Among Female Healthcare Professionals Working In Governmental Hospitals, Addis Ababa, Ethiopia
}

\author{
Seife Teferi Dellie ${ }^{1}$, Teklehaimanot Mezgebe Neguse ${ }^{2}$, Meaza Demissie ${ }^{3}$, A. \\ Durgaprasada $\mathrm{rao}^{4}$ \\ ${ }^{1,2}$ Department of Radiology, College of Health Sciences / Addis Ababa University, Ethiopia, \\ ${ }^{3}$ School of Public Health, College of Health Sciences / Addis Ababa University, Ethiopia, \\ ${ }^{4}$ Department of Nuclear Physics, College of Science and Technology / Andhra University, India)
}

\begin{abstract}
Breast cancer in women is a major health burden both in developed and developing countries. Although there is no cancer registry in Ethiopia cervical and breast cancers are the top two cancer types having a lion's share for the high maternal deaths in the country. Stratified random sampling with proportional allocation and systematic random sampling techniques were employed to assess the knowledge of breast cancer risk factors and practice of breast cancer screening methods among female healthcare professionals in governmental hospitals of Addis Ababa, Ethiopia. Data was analyzed using SPSS version 16 in bivariate analysis. In bivariate analysis age, marital status work experience and educational level had association with study participants' practice of the three breast cancer screening methods. These female health workers who were expected to act as role models and educate the public had adequate knowledge of breast cancer risk factors (85.0\%)), BSE (77.6\%), CBE (71.4\%), and mammography (81.4\%) but poor practice of BSE $(35.5 \%)$, CBE $(32.5 \%)$ and mammography $(16 \%)$.Considering their leading role in breast cancer awareness and information dissemination, efforts should be made by Government to improve practice of breast cancer screening methods among female healthcare professionals.
\end{abstract}

Keywords: Breast Cancer, Breast Cancer Risk-Factors, Breast Screening Method, Practice of Breast Screening

\section{Introduction}

Breast cancer is the most common cancer of women, comprising $23 \%$ of all female cancers around the globe, with an estimated 1.15 million cases diagnosed in 2002 (1-2). It is also the leading cause of cancer mortality among women worldwide, with about 411,000 deaths each year. Approximately 4.4 million women with breast cancer diagnosed in the last 5 years were alive until 2006 (3).

There is a marked geographical variation in incidence rates, being highest in the developed world and lowest in the developing countries of the third world. However, in recent years, the incidence of breast cancer has shown an alarming increasing trend in developing countries (4). It is estimated that $45 \%$ of the 1.35 million new cases diagnosed each year, and more than $55 \%$ of breast cancer related deaths, occur in low- and middle income countries (5).

The causes of breast cancer are not fully known. However, researchers have identified a number of factors that increase one's chances of getting breast cancer. These are called risk factors. Risk factors do not cause breast cancer, but can increase the chances of getting breast cancer. Some women have many risk factors, but never get breast cancer. And, some women have few or no risk factors, but do get the disease (1).

Breast cancer risk factors includes family history of breast cancer; personal history of breast cancer; early menarche (< 12 years); late menopause ( $>55$ years); aging; alcohol; late age at first full-term pregnancy $(>30$ years); never breastfed a child; recent oral contraceptive use; high fat diet; tobacco smoke; obesity (postmenopausal); recent and long-term use of hormone replacement therapy; high-dose radiation to chest; lack of physical activity (6).

Until research uncovers a way to prevent breast cancer or to cure all women regardless of when their tumor is found, early detection will be looked upon as the best hope for reducing the heavy toll of this disease. Fifty years ago, there was no established method for the detection of breast cancer at an early stage or for screening of the general population, but advances in technology, policy recommendations by various organizations, and legal mandates have thoroughly changed that situation. Breast Self Examination (BSE), 
Knowledge About Breast Cancer Risk-Factors, Breast Screening Method And Practice Of Breast

Clinical Breast Examination (CBE) and Mammography are now the mainstays for early detection of breast cancer (7). Screening for early cancer detection has been credited for part of the recent reduction in breast cancer mortality.

Monthly breast self-examination (BSE) is a common method of identifying lumps and other abnormalities in the breast for any signs of abnormality (8-9). BSE in conjunction with screening mammography is currently advocated by many organizations (8) but it is also recommended for younger women starting in their 20s (8)who are not yet being screened by mammography. . BSE was first advocated in the 1940s and 1950s, before the advent of screening mammography. Breast surgeons saw many patients whose tumors were too large for surgical removal, and they believed that regular self-examination of the breasts would result in earlier detection when surgery was still an option. In a developing country like Ethiopia, it is not a realistic approach to pursue a population based mass screening program. Breast Self Examination would be the approach for early detection in limited resources countries (10).

Breast clinical examination by physicians is also widely practiced and advocated for women of all ages. Women in their 20s and 30s should have a CBE as part of a periodic health exam by a health professional preferably every 3 years. Starting at age 40, women should have a CBE by a health professional every year.

Screening mammography is promoted as the key to the continued reduction in breast cancer mortality through early detection. A number of organizations, including the National Cancer Institute (NCI), the American Cancer Society (ACS), and the American College of Radiology, currently recommend women at age 40 and older should have a mammogram every year and should continue to do so for as long as they are in good health. Several randomized controlled studies have been undertaken in four countries to assess the value of screening mammography (11). Most of them demonstrated a substantial reduction in rates of death from breast cancer (about 25 to 30 percent) among women screened by mammography, and meta-analysis has confirmed a clear benefit of screening mammography for women over age 50 (12).

In Ethiopia, communicable and chronic diseases are the major health issues and all the efforts and recourses are engaged into it. Government, non government organizations and international partners all are giving their utmost effort to cope with these diseases. Cancer and particularly breast cancer is on the bottom of their priority list. That's why there is no much infrastructure and facilities to fight against breast cancer in this country.

Again in Ethiopia where literacy rate is not that high; poverty, culture and religion play an important role for health seeking behaviour. Especially for women in rural areas one can easily assume that knowledge will be poor and practice will be even poorer. Furthermore there is lack of a uniform information, education and communication about breast cancer. And this makes difficult to state the exact situation about the knowledge of breast cancer risk factors and practice of breast cancer screening methods in Ethiopia.

Studies have not been conducted so far on the assessment of knowledge and practice of breast cancer among female healthcare professionals (FHPs) in Ethiopia. Hence, findings from this study will provide a starting point for health authorities to raise awareness amongst women about breast cancer and the role of BSE, CBE and Mammography in breast cancer investigation. Moreover, this study would serve as baseline information for future intervention program on breast cancer. Last but not least it will be helpful for health program planners to consider breast cancer in their priority health issues. Therefore, this study was conducted to assess the knowledge about breast Cancer risk-factors, breast screening method and practice of breast screening among female healthcare professionals working in Addis Ababa governmental hospitals

\section{Materials and methods}

According to Health and Health Related Indicators publication by, Addis Ababa had 33 Hospitals, 28 Health Centers and 35 Health Posts (14). There are thirteen governmental hospitals in Addis Ababa namely: St. Paul General Specialized Hospital, Tikur Anbesa Specialised Hospital, St. Peter Hospital, Alert Hospital, Amanuel Hospital, Zeweditu Memorial Hospital, Ras Desta Damitew Hospital, Yekatit 12 Hospital, Menilik II Hospital, Gandhi Memorial Hospital, Armed Forces General Hospital, Bella Defense Referral Hospital and Federal Police Hospital. The total numbers of FHPs with diploma and above in these hospitals were 2332 (Each Hospital, personal communication).

A cross-sectional quantitative study was used to measure the proportion of female healthcare professionals in governmental hospitals of Addis Ababa about breast cancer risk factors related knowledge and practice of BSE, CBE and Mammography. The source population comprises of FHPs working in Addis Ababa governmental hospitals. The study population comprises any female healthcare worker with minimum professional educational level of diploma and currently in medical practice with no past or current history of breast cancer.

The sample size was determined using EPiInfo version 3.5.1 considering 95\% confidence intervals, and $5 \%$ marginal error. However, as estimates of for proportion of FHPs having adequate knowledge and practice were not available for Addis Ababa women it was assumed that $50 \%$ of the patient of the FHPs had adequate knowledge and practice. A total of 442 FHPs were taken including $15 \%$ to compensate for non respondents. 
The sampling technique employed was stratified random sampling with proportional allocation and systematic random sampling. Proportional allocation was used to allocate the total sample size to each hospital.

Data collection was accomplished using self-administered questionnaires designed to obtain relevant sociodemographic characteristics such as age, marital status, level of education, type of profession, work experience and monthly income; knowledge of breast cancer risk factors such as sex, increasing age, positive family history, high fat diet, smoking, alcohol consumption, first child at late age, early onset of menarche, late menopause, lack of physical activity and high-dose radiation to chest; and practice of breast cancer screening methods such as BSE, CBE and mammography.

The FHPs upon receiving the questionnaires were instructed not to discuss the questions among themselves. This was done to avoid contamination and dissemination of knowledge. The questionnaire was also pre-tested on twelve FHPs drawn from Ethio-Tebib Hospital which is private-owned hospital. As a result of this pre-test, modifications were made based on the findings of the pre-test. Finally the questionnaires were distributed to the FHPs through their respective units by one focal person from each unit.

Obtained data was checked for error and then data entry was done using Epi Info version 3.5.1. The entered data was cleaned and analyzed by using SPSS version 16.0. Frequency distributions were produced for the variables and the results were displayed using percentage and frequency tables. Bivariate analysis was applied to explore association of explanatory variables with their practice of BSE, CBE and mammography. Level of statistical significance was set at $\mathrm{P}<0.05$.

Knowledge was assessed by categorizing into four. Excellent knowledge group were those answered 80-100\% correct answers (9-11), very good knowledge group were those answered 60-79\% correct answers (78), good knowledge group were those answered 40-59\% correct answers (5-6) and answered less than $40 \%$ correct answers (0-4) were poor knowledge group (15). The practice of BSE, CBE and mammography of FHPs was categorized into three. Breast cancer screening practices of study participants was graded as good practice $(75-100 \%)$, satisfactory practice $(50-74 \%)$ and poor practice (less than $50 \%$ ) by (Olumuyiwa and Olufemi, 2001).Before conducting the study, the research project ethically cleared by faculty of medicine Institute of Review Board. Ethical clearance and permission was obtained from the respective hospitals. All participants were informed about the purpose of the study and confidentiality of information

\section{Results.}

From the total of 442 FHPs included in the study, 420 FHPs' questionnaires were ready for final data analysis. The participants were between the age group of 20 - 60 years with a mean age of 30.6 years and standard deviation of 8.42 years. By age group, over three-fourth of the study participants $(81.1 \%)$ were aged between 20 to 39 years. Most of the participants were single with $210(50.5 \%)$ respondents and married with $195(46.9 \%)$ respondents. Two hundred and twenty three $(53.1 \%)$ of the study participants were first degree holders. From the total study participants $280(67.5 \%)$ of them were nurses, $31(7.5 \%)$ were physicians, 22 $(5.3 \%)$ were pharmacy professionals, $22(5.3 \%)$ were health officers, $28(6.7 \%)$ were medical laboratory professionals and $32(7.7 \%)$ were radiographers, physiotherapists, anaesthetists, and midwives. The average work experience of the study participants were 7.76 years with standard deviation of 7.96 years. Two hundred and seventy nine $(71.5 \%)$ of the respondents had worked for less than or equal to nine years followed by 63 $(16.2 \%)$ who had worked for ten to nineteen years then $38(9.7 \%)$ and $10(2.6 \%)$ who worked for twenty to twenty nine years and greater than or equal to eighteen years, respectively. Their monthly income ranges from 900 to 4605 Ethiopian birr with a mean monthly salary of 2227 birr (Table 1).

\section{Knowledge of Study Participants about Breast Cancer Risk Factors}

Regarding FHPs responses to questions on breast cancer risk factors (fig1) showed that 348 (84.3\%) knew that a high-dose radiation to chest was a risk factor for the development of breast cancer followed by smoking $339(81.1 \%)$, sex $329(79.1 \%)$ and positive family history $320(77.3 \%)$. Least recognized risk factors were early onset of menarche 160 (39.0\%), first child at late age 187 (45.3\%) and late menopause $210(50.7 \%)$. Overall assessment of their knowledge revealed that $125(30.7 \%)$ had excellent knowledge of risk factors, 108 (26.5\%) possessed very good knowledge, $113(27.8 \%)$ had good knowledge while 61 (15.0\%) had poor knowledge about the risk factors for breast cancer assessed. Only 49 (12.0\%) of participants were able to identify all as risk factors (Figure 2).

\section{Awareness of FHPs about Breast Cancer Screening Methods}

Three hundred and twenty six (77.6\%) respondents were aware of BSE as a screening method. Mammography was mentioned as a screening method by $342(81.4 \%)$ and the least mentioned screening method by the participants was CBE which was known by 300 (71.4\%) respondents. A total of 264 (62.9\%) participants were aware of all three methods of screening, 31 (7.4\%) were aware of two screening methods, $14(27.1 \%)$ were aware of one screening method while $11(2.6 \%)$ were unaware of none of the breast cancer screening methods. 
Knowledge About Breast Cancer Risk-Factors, Breast Screening Method And Practice Of Breast

Their source of information about the screening methods were health professionals $(78.8 \%, 80.2 \%$ and $74.3 \%$ for BSE, CBE and mammography respectively), Television $(32.9 \%, 20.7 \%$ and $21.4 \%$ for BSE, CBE and mammography respectively), Magazine/Newspaper $(21.9 \%, 16.7 \%$ and $14.5 \%$ for BSE, CBE and mammography respectively). They also mentioned other sources of information like radio, friends/ relatives and brochures in lesser percent.

\section{Practice of FHPs in Relation to Breast Cancer Screening Methods}

This study revealed that majority of the respondents, $310(75.1 \%)$ practiced BSE followed by CBE and mammography which was $134(32.5 \%)$ and $65(16.0 \%)$, respectively (Table 2). One hundred and nineteen (35.5\%) of the study participants in this study said BSE should be performed once in a month, $81(24.2 \%)$ once in a week, $26(7.8 \%)$ once in three months, $16(4.8 \%)$ once in 6 months, $15(4.5 \%)$ once in a year, $56(16.7)$ did not know the frequency of practicing BSE and $22(6.6 \%)$ mentioned different times of performing BSE. One hundred and ninety four (57.4\%) of the FHPs started practicing BSE at an age less than 25 years, 73 (21.6\%) started from 25 to 30 years of age, $27(8.0 \%)$ started from 31 to 35 years of age and $44(13.0 \%)$ started from the age greater than 35 years. In relation to CBE $34(19.5 \%)$ of the respondents said it should be practiced monthly, $45(25.9 \%)$ once in a year, $45(25.9 \%)$ every three months, $9(5.2 \%)$ once in three years and $41(23.6 \%)$ do not know how often CBE should be done until a woman should reach 40 years.

The study participants gave different answers to the question "Do you know how often mammography should be done?" $169(46.2 \%)$ said once in a year, $80(21.9 \%)$ every six months, $28(7.7 \%)$ once in two years, $19(5.2 \%)$ once in three years and $70(19.1 \%)$ mentioned different times. The participants responded for the question what is the recommended age of mammography examination to start: $88(21.8 \%)$ reported it should be started at the age of 35, $78(19.3 \%)$ at the age of 30, $54(13.4 \%)$ at the age of 40, $20(5.0 \%)$ at the age of 45 and $164(40.6 \%)$ did not know when to start.

\section{Factors Associated with Practice of Breast Cancer Screening Methods among FHPs}

Marital status was the only variable statistically associated with study participants' practice of BSE.

Age, marital status, educational level, type of profession and work experience had association with study participants' practice of CBE. Age, marital status, educational level, work experience and type of profession were statistically associated with study participants' practice of mammography in bivariate analysis (Table3).

Table 1: Socio-demographic characteristics of FHPs in AAGHs, 2012

\begin{tabular}{cc}
\hline Variable & $\mathrm{N}(\%)$ \\
\hline Age group (in years) & $233(58.7)$ \\
$20-29$ & $89(22.4)$ \\
$30-39$ & $60(15.1)$ \\
$40-49$ & $15(3.8)$ \\
$50^{+}$ & \\
Marital status & $210(50.5)$ \\
Single & $195(46.9)$ \\
Married & $6(1.4)$ \\
Divorced & $5(1.2)$ \\
Widowed & \\
Level of Education & $168(40.0)$ \\
Diploma & $223(53.1)$ \\
Degree (BSc.) & $25(6.0)$ \\
Medical Doctorate (MD) & $4(1.0)$ \\
Others* & \\
Type of Profession & $280(67.5)$ \\
Nurse & $31(7.5)$ \\
Physician & $22(5.3)$ \\
Pharmacy & $22(5.3)$ \\
Health officer & $28(6.7)$ \\
Medical laboratory & $32(7.7)$ \\
Others* & \\
Work Experience (in years) & $279(71.5)$ \\
$<=9$ years & $63(16.2)$ \\
10 to 19 years & $38(9.7)$ \\
20 to 29 years & $10(2.6)$ \\
$30^{+}$years &
\end{tabular}




\section{Monthly income (in Birr)}

$<=1400$

$1401-1800$

$1801-2200$

$60(17.9)$

$2201-2600$

$56(16.7)$

$2601-2989$

$49(14.6)$

$2990^{+}$

$55(16.4)$

*Others: Masters (MSc.) and Sub-Specialization

**Others: Radiographers, Physiotherapists, Anaesthetists and Midwives

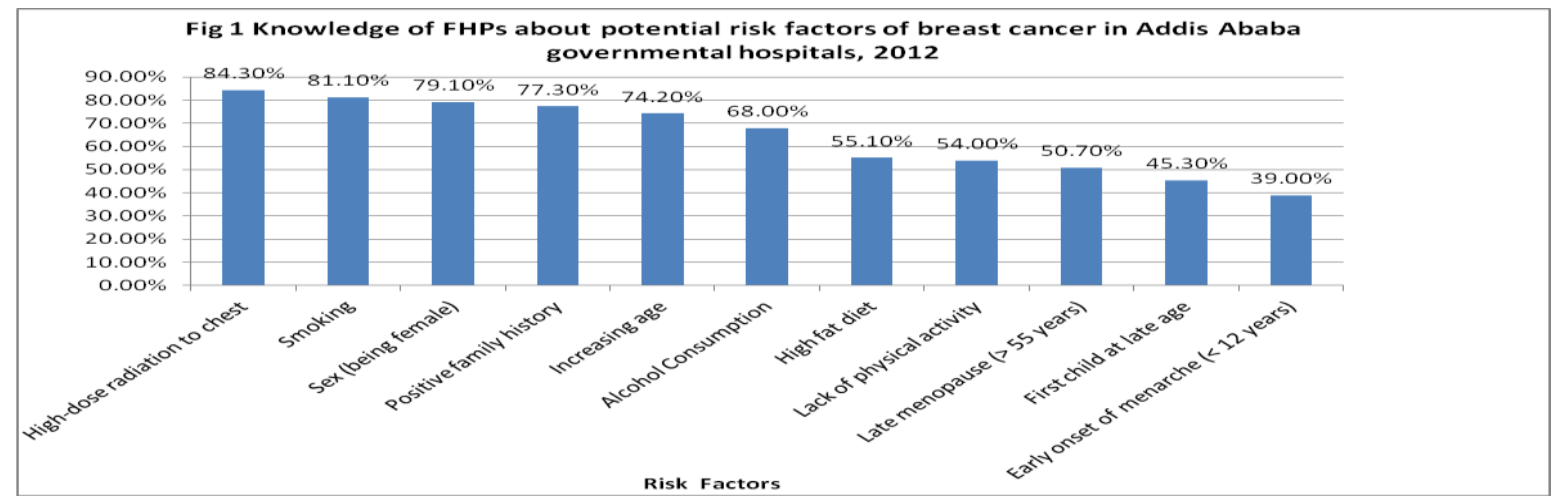

* Percentage will not be added up to $100 \%$ because percentages were analysed independently for each of the variables. In addition to that more than one answer was also possible

Figure 2: Level of knowledge risk factor for FHPs working in Addis Ababa governmental hospitals, 2012

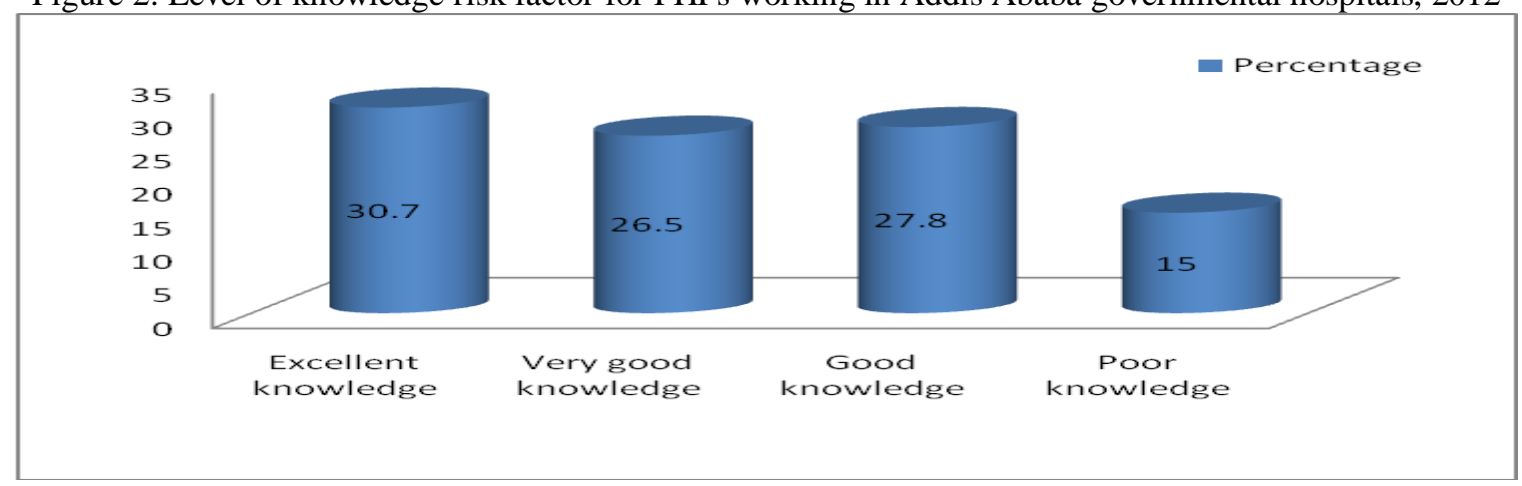

\begin{tabular}{ll}
\hline $\begin{array}{l}\text { Table 2: Practice of FHPs in relation to breast } \\
\text { cancer screening methods in Addis Ababa } \\
\text { governmental hospitals, 2012.Variable }\end{array}$ & $\mathrm{N}(\%)$ \\
\hline & \\
Breast Self Examination & \\
$\quad$ Yes & $310(75.1)$ \\
$\quad$ No & $103(24.9)$ \\
Clinical Breast Examination & \\
$\quad$ Yes & $134(32.5)$ \\
$\quad$ No & $278(67.5)$ \\
Mammography & $65(16.0)$ \\
$\quad$ Yes & $340(80.0)$ \\
$\quad$ No & \\
\hline
\end{tabular}


Table 3: Factors associated with practice of BSE, CBE and mammography among FHPs in Addis Ababa governmental hospitals, 2012

\begin{tabular}{|c|c|c|c|c|c|c|c|c|c|c|c|c|}
\hline \multirow[b]{2}{*}{ Characteristies } & \multicolumn{4}{|c|}{$\begin{array}{l}\text { Practice of } \\
\text { BSE }\end{array}$} & \multicolumn{4}{|c|}{$\begin{array}{l}\text { Practice } \\
\text { of CBE }\end{array}$} & \multicolumn{4}{|c|}{$\begin{array}{l}\text { Practice of } \\
\text { Mammography }\end{array}$} \\
\hline & $\begin{array}{l}\text { No } \\
\text { (n) }\end{array}$ & $\begin{array}{l}\text { Yes } \\
\text { (n) }\end{array}$ & $\begin{array}{l}\operatorname{COR}(95 \% \\
\text { CI) }\end{array}$ & $\begin{array}{l}\text { P. } \\
\text { value }\end{array}$ & $\begin{array}{l}\text { No } \\
\text { (n) }\end{array}$ & $\begin{array}{l}\text { Yes } \\
\text { (n) }\end{array}$ & $\begin{array}{l}\text { COR }(95 \% \\
\text { CI) }\end{array}$ & $\begin{array}{l}\text { P. } \\
\text { value }\end{array}$ & $\begin{array}{l}\text { No } \\
\text { (n) }\end{array}$ & $\begin{array}{l}\text { Yes } \\
\text { (n) }\end{array}$ & $\begin{array}{l}\mathrm{COR}(95 \% \\
\mathrm{CI})\end{array}$ & $\begin{array}{l}\text { P. } \\
\text { value }\end{array}$ \\
\hline \multicolumn{13}{|l|}{ Age in years } \\
\hline $20-29$ & 67 & 163 & Ref & & 181 & 50 & Ref & & 203 & 22 & Ref & \\
\hline $30-39$ & 22 & 67 & $\begin{array}{l}1.252 \\
(0.716, \\
2.190)\end{array}$ & 0.431 & 48 & 37 & $\begin{array}{l}2.790 \\
(1.641, \\
4.745)\end{array}$ & $0.000^{\circ}$ & 68 & 18 & $\begin{array}{l}2.443 \\
(1.236, \\
4.825)\end{array}$ & $0.010^{\circ}$ \\
\hline $\begin{array}{l}40 \text { and } \\
\text { above }\end{array}$ & 8 & 63 & $\begin{array}{l}3.237 \\
(1.471, \\
7.123)\end{array}$ & 0.004 & 35 & 38 & $\begin{array}{l}3.930 \\
(2.254, \\
6.852)\end{array}$ & $0.000^{\circ}$ & 49 & 22 & $\begin{array}{l}4.143 \\
(2.124, \\
8.082)\end{array}$ & 0.000 \\
\hline \multicolumn{13}{|l|}{ Marital status } \\
\hline Single & 62 & 144 & $\begin{array}{l}0.570 \\
(0.361, \\
0.900),\end{array}$ & $\begin{array}{l}0 \\
.016^{*}\end{array}$ & 159 & 46 & $\begin{array}{l}0.378 \\
(0.246, \\
0.581)\end{array}$ & $0.000^{\circ}$ & 182 & 21 & $\begin{array}{l}0.406 \\
(0.232, \\
0.713)\end{array}$ & $0.002^{\circ}$ \\
\hline Married & 40 & 163 & Ref & & 115 & 88 & Ref & & 155 & 44 & Ref & \\
\hline \multicolumn{13}{|l|}{$\begin{array}{l}\text { Educational } \\
\text { level }\end{array}$} \\
\hline Diploma & 44 & 120 & $\begin{array}{l}0.846 \\
(0.537, \\
1.332),\end{array}$ & 0.470 & 93 & 73 & $\begin{array}{l}2.329 \\
(1.527, \\
3.552),\end{array}$ & $0.000^{\circ}$ & 123 & 36 & $\begin{array}{l}2.150 \\
(1.256, \\
3.678),\end{array}$ & $0.005^{\circ}$ \\
\hline Degree & 58 & 187 & Ref & & 181 & 61 & Ref & & 213 & 29 & Ref & \\
\hline \multicolumn{13}{|l|}{$\begin{array}{l}\text { Type of } \\
\text { profession }\end{array}$} \\
\hline Nurse & 67 & 210 & Ref & & 171 & 101 & Ref & & 214 & 53 & Ref & \\
\hline Other HSs & 36 & 95 & $\begin{array}{l}0.842 \\
(0.525, \\
1.350),\end{array}$ & 0.475 & 106 & 29 & $\begin{array}{l}0.463 \\
(0.287, \\
0.748),\end{array}$ & $0.002^{\circ}$ & 122 & 11 & $\begin{array}{l}0.364 \\
(0.183, \\
0.723\end{array}$ & $0.004^{\circ}$ \\
\hline \multicolumn{13}{|l|}{$\begin{array}{l}\text { Work } \\
\text { Experience }\end{array}$} \\
\hline Less than 20 & 87 & 251 & $\begin{array}{l}0.275 \\
(0.096, \\
0.788),\end{array}$ & $0.016^{\circ}$ & 233 & 102 & $\begin{array}{l}0.39 \\
(0.208, \\
0.715),\end{array}$ & 0.003 & 283 & 46 & $\begin{array}{l}0.277 \\
(0.141, \\
0.545),\end{array}$ & $0.000^{\circ}$ \\
\hline 20 and above & 4 & 42 & Ref & & 22 & 25 & Ref & & 29 & 17 & Ref & \\
\hline \multicolumn{13}{|l|}{ Monthly } \\
\hline $\begin{array}{c}\text { Low } \\
\text { income }\end{array}$ & 47 & 127 & $\begin{array}{l}0.654 \\
(0.391, \\
1.096),\end{array}$ & 0.107 & 112 & 60 & $\begin{array}{l}1.194 \\
(0.752, \\
1.897),\end{array}$ & 0.452 & 140 & 29 & $\begin{array}{l}1.243 \\
(0.680, \\
2.271),\end{array}$ & 0.48 \\
\hline $\begin{array}{l}\text { High } \\
\text { income }\end{array}$ & 31 & 128 & Ref & & 107 & 48 & $\operatorname{Ref}$ & & 132 & 22 & Ref & \\
\hline
\end{tabular}

* Stands for the presence of statistical association, Ref= Reference

\section{Discussion}

Breast cancer is the most common type of cancer and the most common cause of cancer-related mortality among women worldwide (6) .The burden, however, is not equally distributed as the burden of breast cancer is growing in the developing world while declining in the West $(6,7)$ The incidence in our country is on the rise as well. Breast cancer risk factor knowledge among FHPs is important so that they can provide appropriate screening recommendations to women with a high risk profile, especially in the Ethiopian context where breast cancer screening is not a national phenomenon.

Our results regarding knowledge about most of the risk factors are quite satisfactory. The findings of this study showed that 125 (30.7\%) study participants had excellent knowledge of risk factors, 108 (26.5\%) possessed very good knowledge, $113(27.8 \%)$ had good knowledge while 61 (15.0\%) had poor knowledge about the risk factors for breast cancer assessed. In contrast to this study, a study conducted in Nigeria among FHPs revealed a result of 29 study participants (14\%) had excellent knowledge of risk factors, $3 \%$ possessed very good knowledge and $45 \%$ had good knowledge while the remaining $37 \%$ had poor knowledge of risk factors assessed(15). Similarly, a cross sectional study conducted in Iran (13) and Nigeria again $(16,18)$ indicated that the respondents' knowledge about breast cancer risk factors was not satisfactory. The difference of this study with these studies regarding knowledge of breast cancer risk factors may come due to difference in educational status, to sample size, study area and accessibility to information, composition of the study population and accessibility to mass media.

Healthcare providers not only play an important role in treating patients but are also responsible for improving patient behaviours and screening, as yearly mammography, breast self examination and clinical breast exam are the single most important step that clinicians can take to reduce suffering and death from breast cancer. Despite the inconclusive evidence, it is thought that BSE makes women more breast aware, which in turn may lead to an earlier diagnosis of breast cancer (17). The rationale behind extending BSE practice as a screening test is the fact that breast cancer is frequently detected by women themselves without any other 
symptoms. A meta-analysis of studies investigating the possible benefits of BSE has shown that regular practice increases the probability of detecting breast cancer at an early stage (7).

In this study three hundred and twenty six (77.6\%) respondents were aware of BSE as a screening method. This finding was higher than the study done on female health workers in Nigerian urban city (18) which was $45.8 \%$. The literature supports the argument that regular practice of BSE influences treatment and survival rates $(6,7)$. In this study, three hundred and ten $(75.1 \%)$ FHPs did BSE though the number of FHPs who practiced BSE once in a month was $119(35.5 \%)$. Therefore practice of BSE by FHPs in this study was poor. Higher rates of BSE practice were found among female health workers in Nigerian urban city (18) in which 95\% carried out the procedure at least once every month and over $89 \%$ reported in an earlier study among nurses in Lagos (19). In contrast, in the study conducted by Haji-Mahmoodi $6 \%$ of the study groups practiced BSE monthly (17). Regarding CBE, this study revealed that 134 (32.5\%) FHPs had their breasts examined by a doctor. Practice of CBE by study participants was also poor in study conducted in Nigeria for instance; only $26 \%$ have had the procedure in the previous one year before the study time (15). Findings from this study showed 5.2\% of the respondents said CBE should be practiced once in three years until a woman should reach 40 years which indicates that the practice of CBE was poorer than the practice of BSE. This finding indicates the advocacy of TV/radio is poor. Our study group consisted of FHPs, to whom TV/radio is readily available which makes it an important information source. It is a considerable finding that Magazine/Newspaper are a relatively poor information source accounting for only $21.9 \%, 16.7 \%$ and $14.5 \%$ for BSE, CBE and mammography respectively. In this health care system, subjects may be informed about breast cancer screening which in turn may be a solution for women who are not health professionals.

In this study, as for awareness of mammography as a screening method, was high (81.4\%). This is almost similar to findings among female health workers in a Nigerian urban city in which they scored high (80.7\%) awareness of screening mammography (18) and among public health nurses in Singapore where the authors reported a very high $(96.1 \%)$ awareness of screening mammography (21). Another interesting similarity was noted in that approximately $84 \%$ of our study population had never had a mammography screening test although $(46.2 \%)$ of them knew that women should have periodic mammographic evaluations and they were aware of the fact that mammography could reveal early occult cancer. In this study a review of descriptive studies that examined variables associated with Mammography revealed that not recommended getting mammography $(30.2 \%)$, insufficient availability of facilities rendering the service $(19.8 \%)$ and fear of results (18.6\%), were the most frequent barriers to the practice of mammography. An extremely low mammography practice of only $3.1 \%$ was found in the study among 162 respondents who were above 40 years of age (18) and this was lower than the report among Nurses in Lagos which was $7.8 \%$ but relatively high rate of practice was found with similar studies in Saudi Arabia that was 42.7\% (22) and Singapore reported as 35\% (20).

In this study marital status had statistical association with study participants' practice of BSE. In a community based study conducted in Nigeria higher level of education and higher knowledge score were significant determinants of BSE practice (20). Other investigators have reported that demographic characteristics such as higher levels of education, income, marital status, younger age, and knowledge were significant determinants of adherence to BSE practice (23). A cross sectional study conducted in Iran (17) inferred that the practice of BSE was significantly associated with age, the level of education and a personal history of breast problems. Findings from this study indicated that age, marital status, educational level, type of profession and work experience had statistical association with study participants' practice of CBE. Rates of BSE and CBE by participants in a study done among FHPs towards breast cancer in a tertiary institution in Lagos, Nigeria (15) were found not to be influenced by age, profession or knowledge of risk factors. This study revealed that age, marital status, educational level, work experience and type of profession were statistically associated with study participants' practice of mammography. The differences observed between this study and other studies in relation to associated factors with practice of breast cancer screening methods may come due to difference in sample size, type of study population and method of analysis applied. There was no international standardized questionnaire on breast cancer knowledge of risk factors and practice of screening methods available and this may serve as a limitation in comparing the findings of this study with other studies.

Levels of knowledge of healthcare providers about breast cancer screening play a significant role in the content of patient education. Studies have shown that knowledgeable healthcare professionals practice CBE and teach women about risks of breast cancer more than healthcare providers who have limited levels of knowledge (24)Awareness of majority of the respondents about BSE, CBE and mammography was generally satisfactory though there was a big discrepancy in practicing them. Generally the FHPs practice of BSE, CBE and mammography on the recommended time and frequency was very poor. Considering their leading role in breast cancer awareness and information dissemination, efforts should be made by Government agencies to improve practice of breast cancer screening methods among healthcare providers.

\section{References}


[2]. Parkin, D.M., Whelan, S.I., Ferlay, J. and Storm, H. 2005. Cancer Incidence in Five Continents, Vol I-VIII. IARC CancerBase no 6., Lyon, IARC Press.

[3]. Parkin, D.M. and Fernandez, L.M. 2006. Use of statistics to assess the global burden of breast cancer. Breast J 12 (1): $70-80$.

[4]. Porter, P. 2008. "Westernizing" women's risks? Breast cancer in lower-income countries. The New England Journal of Medicine 358(3):213-216.

[5]. Curado, MP., Edwards, B. and Shin, H.R. 2007. Cancer Incidence in Five Continents. Vol. IX. Lyon, France: International Agency for Research on Cancer. (IARC Scientific Publications no. 160).

[6]. American Cancer Society, 2007-2008. Breast Cancer Facts \& Figures. Atlanta.

[7]. American Cancer Society, 2005-2006. Breast Cancer Facts \& Figures. Atlanta.

[8]. Smith, R.A., Cokkinides, V. and Eyre, H.J. 2005. American Cancer Society Guidelines for the Early Detection of Cancer. CA Cancer J Clin 55 (1):31-44.

[9]. Ahuja, S., and Chakrabarti, N. 2010. To Determine The Level Of Knowledge Regarding Breast Cancer And To Increase Awareness About Breast Cancer Screening Practices Among A Group Of Women In A Tertiary Care Hospital In Mumbai, India. The Internet Journal of Public Health 1 (1).

[10]. Benjamin, O. A., Susan, B., Susan, L., Robert, A. S., and Stephen, T. 2003. Early detection of breast cancer in countries with limited resources. The breast Journal 9 (1): 51-59.

[11]. Moss MS. Breast cancer. In: Kramer BS, Gohagan JK, Prorok PC, eds. Cancer Screening:Theory and Practice. New York: M. Dekker; 1999:143-170.

[12]. Kerlikowske K, Salzmann P, Phillips KA, Cauley JA, Cummings SR. Continuing screening mammography in women aged 70 to 79 years: impact on life expectancy and costeffectiveness. JAMA. 1999; 282:2156-63.

[13]. CSA, 2007. Central Statistical Agency of Ethiopia: Statistical Report of the 2007. Population and Housing Census

[14]. FMOH, 2008. Planning and Programming Department. Health and Health Related Indicators. Addis Ababa, Ethiopia.

[15]. Nasiru, A. I. and Olumuyiwa, O. O. 2009. Knowledge of risk factors, beliefs and practices of female healthcare profes sionals towards breast cancer in a tertiary institution in Lagos, Nigeria. BMC Cancer 9: 76.

[16]. Michael, N O., Clareann, H B., Friday, E O. and Usifo, O. 2006. Knowledge, attitude and practice of Nigerian women towards breast cancer: A cross-sectional study. World J Surg Oncol 4:11.

[17]. Haji-Mahmoodi, M., Montazeri, A., Jarvandi, S., Ebrahimi, M., Haghighat, S. and Harirchi, I. 2002. Breast self-examination: knowledge, attitudes, and practices among female health care workers in Tehran, Iran. Breast Journal 8(4):222-225.

[18]. Adenike, O. A. and Vivian, O. O. 2009. Knowledge, attitudes and practice of breast cancer screening among female health workers in a Nigerian urban city. BMC Cancer 9:203.

[19]. Olumuyiwa O. O. and Olufemi O. T. 2001. Breast Cancer knowledge, attitudes and practice among nurses in Lagos, Nigeria. Acta Oncologica 40(7):844-848

[20]. Seah, M. and Tan, S.M. 2007. Am I breast cancer smart? Assessing breast cancer knowledge among healthcare professionals. Singapore Medical Journal 48(2):158-162.

[21]. Chong, P.N., Krishnan, M., Hong, C.Y. and Swah, T.S. 2002. Knowlegde and practice of breast cancer screening amongst public health nurses in Singapore. Singapore Medical Journal 43(10): 509-16

[22]. Maha, S.A and Abdel, H. 2000. Breast cancer awareness among health professionals. Annals of Saudi Medicine 20(2):135-6.

[23]. Maxwell, A.E., Bastani, R. and Warda, U.S. 2000. Demographic predictors of cancer screening among Filipino and Korean immigrants in the United States. Am J Prev Med 18(1): 62-68.

[24]. Odusanya, O.O., Tayo, O.O. Breast cancer knowledge, attitudes, and practice among nurses in Lagos, Nigeria. Acta Oncologica, (2001). 40, 844-848.

ACKNOWLEDGMENT: we gratefully acknowledge all hospitals that participated in this study and their staff for their cooperation. The authors also express their gratitude to all health professionals participated in data collection. 